\title{
Oestrogen metabolites in relation to isoprostanes as a measure of oxidative stress
}

\author{
MaryFran Sowers*†, Daniel McConnell*, Mary L. Jannausch*, John F. Randolph Jrt, Robert Brookł, \\ Ellen B. Gold§, Sybil Crawfordף and Bill Lasley**
}

${ }^{\star}$ Department of Epidemiology, School of Public Health, University of Michigan, Ann Arbor, MI, †Department of Obstetrics and Gynecology, University of Michigan Health Sciences System, Ann Arbor, MI, $\ddagger$ Department of Cardiovascular Medicine, University of Michigan Health Sciences System, Ann Arbor, MI, \$Division of Epidemiology, Department of Public Health Sciences, University of California School of Medicine, Davis, CA, Division of Preventive and Behavioral Medicine, University of Massachusetts Medical School, Worcester, MA and ${ }^{\star \star}$ Department of Population Health and Reproduction, University of California, Davis, CA, USA

\section{Summary}

Objective Oestradiol (E2) and its metabolites 2-hydroxyoestrone (2-OHE1) and $16 \alpha$-hydroxyoestrone (16 $\alpha$-OHE1) are thought to curtail the greater oxidative stress found in the development and progression of disease conditions including atherosclerosis. We related oestrogen levels to $\mathrm{F}_{2 \mathrm{a}}$-isoprostane levels, a biomarker of oxidative stress.

Design and participants Data were obtained from 1647 women, aged 47-57 years, participating in the fifth annual follow-up of the Study of Women's Health Across the Nation (SWAN), a study of the menopausal transition.

Measurements Serum E2 and urinary 2-OHE1 and 16 $\alpha$-OHE1 concentrations were determined by enzyme-linked immunosorbent assay (ELISA) and urinary $\mathrm{F}_{2 \mathrm{a}}$-isoprostanes were measured by enzyme immunoassay (EIA).

Results $\mathrm{F}_{2 \mathrm{a}}$-isoprostane concentrations were elevated in women who smoked, a behaviour associated with increased oxidative stress, but not in stages of the natural menopause. Mean $\mathrm{F}_{2 \mathrm{a}}$-isoprostane concentrations among pre- and postmenopausal women who smoked were 1082 and $1064 \mathrm{pg} / \mathrm{ml}$, respectively, values double those in pre- $(343 \mathrm{pg} / \mathrm{ml})$ and postmenopausal $(379 \mathrm{pg} / \mathrm{ml})$ nonsmoking women. 2-OHE1 and $\mathrm{F}_{2 \mathrm{a}}$-isoprostane concentrations were positively and highly correlated (partial correlations $\rho_{\mathrm{Y} \mid \mathrm{X}}=0.44$ and $\rho_{\mathrm{Y} \mid \mathrm{X}}=0.43$ in pre- and postmenopausal women, respectively). Similarly, $16 \alpha$ OHE1 concentrations were positively and highly correlated with $F_{2 a}$-isoprostane concentrations $\left(\rho_{\mathrm{Y} \mid \mathrm{X}}=0.52\right.$ and $\rho_{\mathrm{Y} \mid \mathrm{X}}=0.59$ in preand postmenopausal women, respectively). E2 was significantly correlated with $\mathrm{F}_{2 \mathrm{a}}$-isoprostanes only in postmenopausal women $\left(\rho_{\mathrm{Y} \mid \mathrm{X}}=0 \cdot 20\right)$. Associations were adjusted for age, body mass index

Correspondence: MaryFran Sowers, Department of Epidemiology, School of Public Health, University of Michigan, 339 E. Liberty St, Suite 310, Ann Arbor, MI 48104, USA. Tel.: (+1) 734936 3892; Fax: (+1) 734998 8027; E-mail:mfsowers@umich.edu
(BMI), race/ethnicity, lipids, physical activity level and alcohol consumption.

Conclusions This study does not support the commonly held hypothesis that levels of endogenous E2 or its oestrone metabolites favourably modify oxidative stress by decreasing $\mathrm{F} 2$-isoprostane levels.

(Received 11 July 2007; returned for revision 4 August 2007; finally revised 26 September 2007; accepted 26 September 2007)

\section{Introduction}

It has been hypothesized that physiological levels of oestradiol (E2) and oestrogen metabolites, including 2-hydroxyoestrone (2-OHE1) and $16 \alpha$-hydroxyoestrone (16 $\alpha$-OHE1), favourably modulate oxidative stress, potentially attenuating the development and progression of disease, including atherosclerosis and diabetes. ${ }^{1,2}$ While the concept of oestrogens as antioxidants is intriguing and might explain differential rates or timing of cardiovascular disease between men and women, the evidence remains controversial.

High, nonphysiological levels of E2 were found to be associated with the in vitro inhibition of low density lipoprotein (LDL) oxidation, ${ }^{3,4}$ a prominent feature of atherosclerosis. ${ }^{5,6}$ Some, ${ }^{7,8}$ but not all, studies ${ }^{9,10}$ have shown that, in postmenopausal women, oestrogen replacement diminished circulating oxidized LDL levels. Studies of oxidative stress according to sex difference or menopause transition to postmenopause are too few in number to clarify the role of oestrogens as antioxidants. Ide et al. reported that urinary levels of $\mathrm{F}_{2 \mathrm{a}}$-isoprostanes are increased in healthy young men compared to premenopausal women; ${ }^{11}$ however, two other studies ${ }^{12,13}$ reported that $\mathrm{F}_{2 \mathrm{a}}$-isoprostane levels were about $20 \%$ lower, not higher, in men as compared to women. Helmersson et al. reported increased levels in postmenopausal compared to premenopausal women. ${ }^{14}$

Using $\mathrm{F}_{2 \mathrm{a}}$-isoprostane production as a marker for identifying oxidative stress, ${ }^{15,16}$ we examined the potential antioxidant associations of oestrogens considering stages of menopause. We hypothesized 
that an important antioxidant role for E2, 2-OHE1 and 16 $\alpha$-OHE1 would be reflected in strong, inverse correlations with $\mathrm{F}_{2 \mathrm{a}}$-isoprostanes. We postulated that the associations between oestrogens and the $\mathrm{F}_{2 \mathrm{a}}$-isoprostanes would be similar in pre- and postmenopausal women using hormone therapy (HT), and dissimilar to the associations in postmenopausal women without HT use. These hypotheses were tested while adjusting for lipids, body mass index (BMI), race/ethnicity, smoking, exercise, vitamin $\mathrm{E}$ and iron supplementation and substantial alcohol consumption. ${ }^{17}$

\section{Methods}

\section{Sampling and study population}

Data were from 1647 enrolees at the fifth annual follow-up visit of the Study of Women's Health Across the Nation (SWAN), a community-based, longitudinal study of the menopausal transition. ${ }^{18}$ Eligible participants were from Boston MA, Chicago IL, the Detroit area MI, Los Angeles CA, Hudson County NJ, Oakland CA, and Pittsburgh PA. At baseline, eligibility criteria for the longitudinal cohort were: age 42-52 years; intact uterus and at least one ovary; no current use of oestrogens or other medications known to affect ovarian function; at least one menstrual period in the 3 months before enrolment; and self-identification as a member of one of the five eligible racial/ethnic groups. The sites enrolled a Caucasian and non-Caucasian sample including African-American women in Boston, Chicago, the Detroit area and Pittsburgh, and Japanese, Chinese and Hispanic women in Los Angeles, Oakland and New Jersey, respectively. Two sites, Chicago and Newark, did not collect annual urine samples from enrolees so the only contribution for these sites comes from 44 women at the Chicago site who provided urine samples for a SWAN substudy. There was Institutional Review Board approval for the study protocol at each study site and all subjects gave their informed consent.

\section{Assays}

This study was limited to specimens collected during the fifth annual follow-up examination and available through the SWAN Repository. When possible, early morning blood draws occurred in the fasted state during days $2-5$ of the early follicular phase of the menstrual cycle. Urine specimens for the $\mathrm{F}_{2 \mathrm{a}}$-isoprostane analyses and oestrone metabolites were collected on the days of blood draw (usually on days $2-5$ of the early follicular phase and, by protocol, prior to $1100 \mathrm{~h}$ ). At the fifth follow-up visit, $96 \%$ of samples were acquired fasting, $97 \%$ were acquired before $1100 \mathrm{~h}$, and $53 \%$ of samples were collected in days $2-5$ of the follicular phase of the menstrual cycle. Assays were completed in the CLASS laboratory, University of Michigan.

Serum E2 concentrations were measured with a modified, off-line ACS:180 (E2-6) immunoassay (Bayer Diagnostics Corp., Norwood, MA). The assay range for E2 was calibrated to address the lower values associated with the follicular phase or with the postmenopause. Inter- and intra-assay coefficients of variation (CVs) were $10 \cdot 6 \%$ and $6 \cdot 4 \%$, respectively, over the assay range $20-500 \mathrm{pg} / \mathrm{ml}$.

2 -OHE1 and $16 \alpha$-OHE1 were assayed by enzyme immunoassay (EIA; ESTRAMET ${ }^{\mathrm{TM}}$ ) in triplicate. ${ }^{19}$ The inter- and intra-assay CVs were less than $10 \%$ for each analyte. Because urinary forms of 2-OHE1 and 16 $\alpha$-OHE1 are found as 3-glucuronides or 3,3,16glucuronides, it was necessary to remove these sugars to achieve recognition sites for the monoclonal antibodies. Therefore, the oestrogens were deconjugated from glucuronic acid and sulfate using a mixture of $\beta$-glucuronidase and arylsulfatase enzyme isolated from the snail Helix pomatia. The assay range was $0 \cdot 6-40 \cdot 0 \mathrm{ng} / \mathrm{ml}$.

Samples were purified with $\mathrm{F}_{2 \mathrm{a}}$-isoprostane affinity columns according to the manufacturer's instructions (Cayman Chemical, Ann Arbor, MI). Samples were applied to the column, washed with buffer and eluted with 95\% ethanol. Following evaporation of solvent, the dried samples were diluted $1: 10$ with $0 \cdot 1 \mathrm{M}$ phosphate buffer and assayed using the $\mathrm{F}_{2 \mathrm{a}}$-isoprostane EIA kit (Cayman Chemical). The standard curve range was 3.9-500 pg/ml. Samples were read at $405 \mathrm{~nm}$ in a 96 -well microplate reader. The postextraction intra- and interassay CVs were $14.4 \%(51.2 \mathrm{pg} / \mathrm{ml}, n=83$ pairs $)$ and $17 \cdot 5 \%(51.2 \mathrm{pg} / \mathrm{ml}, n=85)$, respectively; the intra-assay $\mathrm{CV}$ was $5 \cdot 8 \%$ ( $n=1707$ pairs).

Lipids were assayed at the Medical Research Laboratories, Highland Heights, KY, which is certified by the Centers for Disease Control Lipid Standardization Part III program. ${ }^{20}$ All lipid and lipoprotein fractions were analysed on ethylenediaminetetraacetic acid (EDTA)-treated plasma. Total cholesterol and triglycerides were analysed by enzymatic methods and high density lipoprotein cholesterol (HDL-C) was isolated using heparin-2 $\mathrm{M}$ manganese chloride. Participants were classified as diabetic based on a fasting glucose $\geq 126 \mathrm{mg} / \mathrm{dl}$ (measured using a hexokinase-coupled reaction on a Hitachi 747-200; Boehringer Mannheim Diagnostics, Indianapolis, IN) or self-reported use of insulin or oral medications for diabetes.

\section{Physical and interview-based measures}

Weight $(\mathrm{kg})$ was measured using a balance beam and electronic scales; height $(\mathrm{m})$ was measured using stadiometers. The data were used to calculate BMI (weight in kilograms divided by height squared in metres).

Women were designated as pre- or perimenopausal unless they had 12 months of amenorrhoea and then they were designated as postmenopausal. Because of their limited number, women who had surgical menopause were excluded from these data analyses. Use of exogenous hormones (HT) was self-reported.

Data on smoke exposure were obtained from a self-administered questionnaire incorporating American Thoracic Society questions ${ }^{21}$ and validated questions on passive exposure. ${ }^{22}$ Baseline leisure physical activity was based on the frequency, intensity and duration of the two sports or exercise activities reported by the participant as occurring in the year prior to assessment. ${ }^{23}$ Estimates of usual annual dietary data were obtained using a modified Block food frequency interviewer-assisted questionnaire (FFQ), ${ }^{24}$ administered in four languages, English, Spanish, Chinese or Japanese. Serving sizes were reported with the assistance of food models. Genistein and daidzein intakes ${ }^{25}$ and polyphenol levels were evaluated. ${ }^{26}$ Total alcohol consumption per day was categorized as none, less than half a serving $(<15 \mathrm{~g})$, and at least half a serving $(\geq 15 \mathrm{~g})$. Vitamin and mineral supplement use was self-reported. 


\section{Statistical approach}

Analyses were conducted using SAS version 9.1 software. Information was excluded from the baseline enrolment of 3302 women for the following reasons: attrition by the fifth annual follow-up visit $(n=696)$ and unavailable oestrogen metabolite data because the protocol at two sites did not include annual urine collection $(n=571)$. Of the remaining 2035 participants, 42 women had surgical menopause and 346 did not have repository specimens available for analyses. The final analytical sample consisted of 371 (23\%) African-American, 837 (51\%) Caucasian, $202(12 \%)$ Chinese and 237 (14\%) Japanese women.

Median and interquartile ranges (IQRs) were calculated for continuous variables, including 2-OHE1 and 16 $\alpha$-OHE1, serum E2, $\mathrm{F}_{2 \mathrm{a}}$-isoprostanes, lipids, BMI and age. All continuous variables except for age were log-transformed to satisfy the normality assumption in parametric testing. Analyses of covariance (ANCOVAs) and multiple variable regression analyses were the primary statistical approaches. Type III sums of squares were used to estimate the adjusted correlations. Adjusted group means were identified using ANCOVAs and comparison of the pairwise differences. $P$-values were two-sided at $\alpha<0 \cdot 05$. Ninety-five per cent confidence intervals (CIs) were used to describe statistical probabilities of associations with ANCOVA models.
Data were stratified by current smoking behaviour because smoking behaviour had a strong main effect and interaction with menopause status. A potential statistical interaction with race could not be tested because smoking was infrequently reported by Chinese or Japanese women, making full statistical adjustment or interaction testing inappropriate. Data were adjusted for age, BMI, race, physical activity level, and lipids as continuous variables. Adjustment also included vitamin E supplement use, iron supplement use, and diabetes as categorical variables. There were no associations with intakes of dietary fat, dietary genistein, daidzein, or polyphenol consumption.

\section{Results}

The overall median age at the fifth annual visit was 51 years, with premenopausal women slightly younger (50 years) and postmenopausal women slightly older (53 years). The median BMI was $26.5 \mathrm{~kg} / \mathrm{m}^{2}$ (Table 1 ). $\mathrm{F}_{2 \mathrm{a}}$-isoprostane concentrations were significantly and markedly different in smokers $v s$. nonsmokers before and after adjusting for covariates. As shown in Fig. 1, $\mathrm{F}_{2 \mathrm{a}}$-isoprostane concentrations in smokers were almost double the mean level of nonsmokers in both African-American and Caucasian women, with few smokers among Chinese and Japanese women.

\begin{tabular}{|c|c|c|c|}
\hline Attribute & $\begin{array}{l}\text { Pre- and } \\
\text { perimenopausal }\end{array}$ & Postmenopausal & HT users \\
\hline Age (years) & $50 \cdot 0(48-51)$ & $53 \cdot 0(51-54)$ & $52 \cdot 0(50-54)$ \\
\hline BMI $\left(\mathrm{kg} / \mathrm{m}^{2}\right)$ & $26 \cdot 5(23-32)$ & $27 \cdot 0(23-32)$ & $26 \cdot 0(23-31)$ \\
\hline Waist circumference $(\mathrm{cm})$ & $84 \cdot 2(74-97)$ & $86 \cdot 3(74-100)$ & $83 \cdot 3(74-96)$ \\
\hline Oestradiol (pg/ml) & $38 \cdot 4(20-79)$ & $13 \cdot 2(10-21)$ & $39 \cdot 5(22-68)$ \\
\hline 2-Hydroxyoestrone (pg/ml) & $8 \cdot 7(5-15)$ & $5 \cdot 3(3-9)$ & $17 \cdot 3(8-41)$ \\
\hline 16 $\alpha$-Hydroxyoestrone $(\mathrm{pg} / \mathrm{ml})$ & $6 \cdot 1(4-10)$ & $4 \cdot 3(3-6)$ & $9 \cdot 0(5-18)$ \\
\hline $\mathrm{F}_{2 \mathrm{a}}$-isoprostanes $(\mathrm{pg} / \mathrm{ml})$ & $433(235-785)$ & $413(231-747)$ & $495(262-872)$ \\
\hline FSH $(\mathrm{mIU} / \mathrm{ml})$ & $22 \cdot 5(12-54)$ & $87 \cdot 3(62-116)$ & $46 \cdot 2(25-71)$ \\
\hline \multicolumn{4}{|l|}{ Race } \\
\hline African-American & $205(22 \cdot 7)$ & $99(26 \cdot 2)$ & $66(18 \cdot 1)$ \\
\hline Caucasian & $445(49 \cdot 3)$ & $168(44 \cdot 4)$ & $223(61 \cdot 1)$ \\
\hline Chinese & $114(12 \cdot 7)$ & $54(14 \cdot 3)$ & $34(9 \cdot 3)$ \\
\hline Japanese & $138(15 \cdot 3)$ & $57(15 \cdot 1)$ & $42(11 \cdot 5)$ \\
\hline \multicolumn{4}{|l|}{ Smoking } \\
\hline Current & $99(11 \cdot 0)$ & $50(13 \cdot 2)$ & $37(10 \cdot 1)$ \\
\hline Not smoking & $803(89 \cdot 0)$ & $328(86 \cdot 8)$ & $328(89 \cdot 9)$ \\
\hline \multicolumn{4}{|l|}{ Exercise } \\
\hline Lowest two quintiles & $332(37 \cdot 6)$ & $157(42 \cdot 9)$ & $134(37 \cdot 8)$ \\
\hline Middle two quintiles & $373(42 \cdot 2)$ & $136(37 \cdot 2)$ & $144(40 \cdot 7)$ \\
\hline Highest quintile & $179(20 \cdot 2)$ & $73(19 \cdot 9)$ & $76(21 \cdot 5)$ \\
\hline \multicolumn{4}{|l|}{ Alcohol consumption } \\
\hline More than half a serving/day & $163(18 \cdot 8)$ & $70(19 \cdot 0)$ & $90(25 \cdot 1)$ \\
\hline Less than half a serving/day & $268(31 \cdot 0)$ & $94(25 \cdot 5)$ & $105(29 \cdot 3)$ \\
\hline None & $434(50 \cdot 2)$ & $204(55 \cdot 5)$ & $163(45 \cdot 6)$ \\
\hline \multicolumn{4}{|l|}{ Diabetes } \\
\hline Yes & $69(8 \cdot 2)$ & $42(11 \cdot 6)$ & $34(9 \cdot 7)$ \\
\hline No & $767(91 \cdot 8)$ & $320(88 \cdot 4)$ & $317(90 \cdot 3)$ \\
\hline
\end{tabular}

Table 1. Characteristics of 1647 participants at the fifth follow-up SWAN examination (excluding women with hysterectomy)

Values are given as $n(\%)$ or median (interquartile range). 


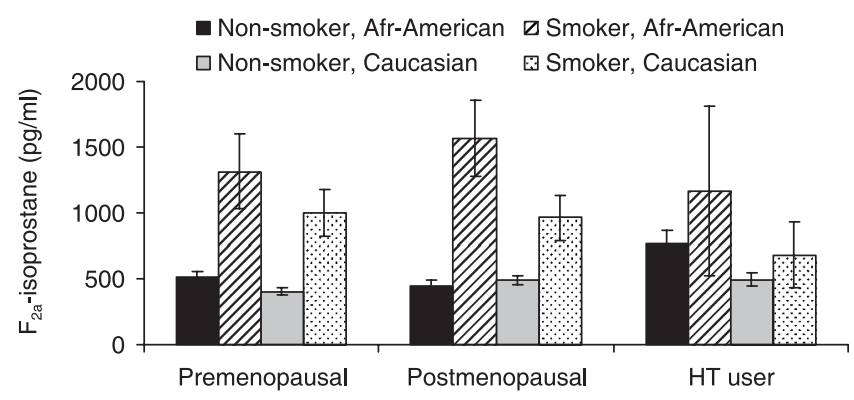

Fig. $1 \mathrm{~F}_{2 \mathrm{a}}$-isoprostane concentrations among premenopausal women, postmenopausal women, and hormone therapy (HT) users, by race and smoking status at the fifth follow-up SWAN examination.

\section{Nonsmokers}

There were no statistically significant differences observed in mean $\mathrm{F}_{2 \mathrm{a}}$-isoprostane concentrations in pre- $v s$. postmenopausal stages (343 vs. $379 \mathrm{pg} / \mathrm{ml}, P=0.09$ ) among women who did not smoke (Table 2). The mean $\mathrm{F}_{2 \mathrm{a}}$-isoprostane concentration in women using HT ( $425 \mathrm{pg} / \mathrm{ml}$ ) was $24 \%$ higher than the mean for premenopausal women $(P=0 \cdot 0002)$. In nonsmokers, the mean E2 concentrations in premenopausal women and HT users were similar $(P=0 \cdot 26)$ but were markedly lower $(-62 \%, P<0 \cdot 0001)$ in postmenopausal women as compared to premenopausal women (Table 2). The mean 2OHE1 concentration in postmenopausal women was $34 \%$ lower $(P<0 \cdot 0001)$ than in premenopausal women. Women using HT had a mean 2-OHE1 concentration $107 \%(P<0.0001)$ higher than premenopausal women. Compared to premenopausal women, the mean 16 $\alpha$-OHE1 concentration was $24 \%(P<0 \cdot 0001)$ lower in postmenopausal women and $76 \%(P<0.0001)$ higher in women using HT.

\section{Smokers}

Among smokers, mean $\mathrm{F}_{2 \mathrm{a}}$-isoprostane concentrations for women who were premenopausal, postmenopausal or using HT were 1082, 1064 and $871 \mathrm{pg} / \mathrm{ml}$, respectively. These values were not statistically different from each other. In addition, the mean E2 concentration in premenopausal women smokers was greater than in postmenopausal women smokers $(35 \cdot 7$ vs. $19 \cdot 1 \mathrm{pg} / \mathrm{ml}, P<0 \cdot 004)$. E2 concentrations in women using HT were somewhat higher than in premenopausal women ( $46 \cdot 1 \mathrm{pg} / \mathrm{ml}, P=0 \cdot 24)$. Among smokers, mean 2-OHE1 concentrations for women who were premenopausal, postmenopausal or using HT were $12 \cdot 5,7 \cdot 3$ and $29 \cdot 8 \mathrm{pg} / \mathrm{ml}$, respectively. These values were significantly different from each other. Mean $16 \alpha$-OHE1 levels for women smokers who were premenopausal, postmenopausal or using HT were $8 \cdot 8,6 \cdot 5$ and $11.3 \mathrm{pg} / \mathrm{ml}$, respectively, values that were not statistically significantly different from each other (see Table 2 ).

\section{Associations of oestrogens with isoprostanes}

As shown in Table 3, among nonsmoking women, E2 concentrations were not significantly associated with $\mathrm{F}_{2 \mathrm{a}}$-isoprostanes in premenopausal women or in those who used HT. In postmenopausal women, the partial correlation was $\rho_{\mathrm{Y} \mid \mathrm{X}}=0 \cdot 20$ (95\% CI 0.08-0 31). This and all subsequent partial correlations include adjustment for age, BMI, race, lipids, menopausal status, exercise, alcohol consumption and diabetes.

In women who did not smoke, consistent, substantial and positive associations were observed between 2-OHE1 and $\mathrm{F}_{2 \mathrm{a}}$-isoprostane concentrations in women using hormones $\left(\rho_{\mathrm{Y} \mid \mathrm{X}}=0 \cdot 39\right)$, in postmenopausal women $\left(\rho_{Y \mid X}=0.43\right)$ and in premenopausal women $\left(\rho_{\mathrm{Y} \mid \mathrm{X}}=0 \cdot 44\right) .16 \alpha-\mathrm{OHE} 1$ concentrations were highly and positively associated with $\mathrm{F}_{2 \mathrm{a}}$-isoprostane concentrations in premenopausal women $\left(\rho_{Y \mid X}=0.52\right)$, postmenopausal women $\left(\rho_{Y \mid X}=0.59\right)$ and women using HT $\left(\rho_{\mathrm{Y} \mid \mathrm{X}}=0 \cdot 46\right)$ (see Table 3 ).

Among women who smoked, $\mathrm{F}_{2 \mathrm{a}}$-isoprostane levels were not significantly associated with E2 concentrations. $\mathrm{F}_{2 \mathrm{a}}$-isoprostane levels were positively associated with 2-OHE1 concentrations in premenopausal women and in women who reported HT use $\left(\rho_{Y \mid X}=0 \cdot 28\right.$ and $0 \cdot 55$, respectively), as well as in postmenopausal women $\left(\rho_{Y \mid X}=0.39\right)$ after adjustment for covariates. $F_{2 a}$-isoprostane levels were positively associated with $16 \alpha$-OHE1 concentrations in premenopausal women $\left(\rho_{\mathrm{Y} \mid \mathrm{X}}=0 \cdot 39\right)$, postmenopausal women $\left(\rho_{Y \mid X}=0 \cdot 64\right)$, and women using HT $\left(\rho_{Y \mid X}=0 \cdot 58\right)$.

The patterns between oestrogens and $\mathrm{F}_{2 \mathrm{a}}$-isoprostanes were similar even when data were stratified by race groups or BMI categories of obesity (data not shown).

\section{Discussion}

It has been argued ${ }^{9}$ that oestrogens might exert antioxidant actions in modifying $\mathrm{F}_{2 \mathrm{a}}$-isoprostane production because of the presence of

Table 2. Mean (SEM) of oestrogen levels (pg/ml) by smoking and menopausal status at the fifth follow-up SWAN examination, adjusted for covariates ${ }^{\star}$

\begin{tabular}{|c|c|c|c|c|c|c|}
\hline & \multicolumn{3}{|l|}{ Non-smokers } & \multicolumn{3}{|l|}{ Smokers } \\
\hline & $\begin{array}{l}\text { Premenopausal } \\
n=803\end{array}$ & $\begin{array}{l}\text { Postmenopausal } \\
n=328\end{array}$ & $\begin{array}{l}\text { Using HT } \\
n=328\end{array}$ & $\begin{array}{l}\text { Premenopausal } \\
n=99\end{array}$ & $\begin{array}{l}\text { Postmenopausal } \\
n=50\end{array}$ & $\begin{array}{l}\text { Using HT } \\
n=37\end{array}$ \\
\hline Oestradiol (pg/ml) & $38 \cdot 9(2 \cdot 4)$ & $14 \cdot 7(0 \cdot 9)$ & $36 \cdot 0(1 \cdot 5)$ & $35 \cdot 7(4 \cdot 5)$ & $19 \cdot 4(3 \cdot 2)$ & $46 \cdot 1(8 \cdot 4)$ \\
\hline 2-Hydroxyoestrone (pg/ml) & $7 \cdot 4(0 \cdot 3)$ & $4 \cdot 9(0 \cdot 3)$ & $15 \cdot 3(0 \cdot 9)$ & $12 \cdot 5(1 \cdot 6)$ & $7 \cdot 3(1 \cdot 2)$ & $29 \cdot 8(5 \cdot 5)$ \\
\hline $16 \alpha$-Hydroxyoestrone $(\mathrm{pg} / \mathrm{ml})$ & $5 \cdot 4(0 \cdot 2)$ & $4 \cdot 1(0 \cdot 02)$ & $9 \cdot 5(0 \cdot 05)$ & $8 \cdot 8(1 \cdot 1)$ & $6 \cdot 5(1 \cdot 0)$ & $11 \cdot 3(2 \cdot 0)$ \\
\hline $\mathrm{F}_{2 \mathrm{a}}$-isoprostanes $(\mathrm{pg} / \mathrm{ml})$ & $343(12 \cdot 4)$ & $379(19 \cdot 5)$ & $425(21 \cdot 9)$ & $1082(139 \cdot 6)$ & $1064(174 \cdot 1)$ & $871(159 \cdot 6)$ \\
\hline
\end{tabular}

${ }^{\star}$ Adjusted for age, BMI, race, lipids, menopausal status, exercise, alcohol consumption and diabetes. 
Table 3. Pearson ( $\rho, 95 \%$ confidence intervals) and partial Pearson correlations ( $\rho_{Y \mid X}, 95 \%$ confidence intervals) between $F_{2 a}$-isoprostane concentrations and oestrogen measures, by menopause and smoking status

\begin{tabular}{|c|c|c|c|c|c|c|}
\hline & \multicolumn{2}{|c|}{ Premenopausal } & \multicolumn{2}{|c|}{ Postmenopausal } & \multicolumn{2}{|c|}{ Using hormones } \\
\hline & $\rho^{*}$ & $95 \%$ CI & $\rho^{*}$ & $95 \%$ CI & $\rho^{*}$ & $95 \%$ CI \\
\hline Nonsmokers & $n=778$ & & $n=323$ & & $n=325$ & \\
\hline \multicolumn{7}{|l|}{ Unadjusted } \\
\hline Oestradiol (pg/ml) & $0 \cdot 13$ & $0 \cdot 06-0 \cdot 20$ & $0 \cdot 31$ & $0 \cdot 21-0 \cdot 41$ & $0 \cdot 04$ & $-0 \cdot 07$ to $0 \cdot 15$ \\
\hline 2-Hydroxyoestrone (pg/ml) & $0 \cdot 43$ & $0 \cdot 37-0 \cdot 49$ & $0 \cdot 43$ & $0 \cdot 33-0 \cdot 51$ & $0 \cdot 34$ & $0 \cdot 24-0 \cdot 44$ \\
\hline $16 \alpha$-Hydroxyoestrone (pg/ml) & $0 \cdot 57$ & $0 \cdot 52-0 \cdot 62$ & $0 \cdot 60$ & $0 \cdot 53-0 \cdot 67$ & $0 \cdot 44$ & $0 \cdot 35-0.52$ \\
\hline \multicolumn{7}{|l|}{ Adjusted $^{*}$} \\
\hline Oestradiol $(\mathrm{pg} / \mathrm{ml})$ & $0 \cdot 08$ & $0 \cdot 00-0 \cdot 15$ & $0 \cdot 20$ & $0 \cdot 08-0 \cdot 31$ & $0 \cdot 02$ & $-0 \cdot 09$ to $0 \cdot 14$ \\
\hline 2-Hydroxyoestrone (pg/ml) & $0 \cdot 44$ & $0 \cdot 38-0 \cdot 50$ & $0 \cdot 43$ & $0 \cdot 33-0 \cdot 52$ & $0 \cdot 39$ & $0 \cdot 29-0 \cdot 49$ \\
\hline $16 \alpha$-Hydroxyoestrone $(\mathrm{pg} / \mathrm{ml})$ & $0 \cdot 52$ & $0 \cdot 47-0 \cdot 57$ & $0 \cdot 59$ & $0 \cdot 51-0 \cdot 66$ & $0 \cdot 46$ & $0 \cdot 36-0 \cdot 54$ \\
\hline Smokers & $n=87$ & & $n=44$ & & $n=33$ & \\
\hline \multicolumn{7}{|l|}{ Unadjusted } \\
\hline Oestradiol $(\mathrm{pg} / \mathrm{ml})$ & $-0 \cdot 007$ & $-0 \cdot 22$ to $0 \cdot 21$ & $0 \cdot 28$ & -0.03 to 0.55 & $0 \cdot 04$ & $-0 \cdot 31$ to $0 \cdot 38$ \\
\hline 2-Hydroxyoestrone (pg/ml) & $0 \cdot 22$ & $0 \cdot 01-0 \cdot 41$ & $0 \cdot 45$ & $0 \cdot 18-0 \cdot 66$ & $0 \cdot 49$ & $0 \cdot 18-0 \cdot 71$ \\
\hline 16 $\alpha$-Hydroxyoestrone (pg/ml) & $0 \cdot 36$ & $0 \cdot 16-0 \cdot 53$ & $0 \cdot 62$ & $0 \cdot 40-0 \cdot 78$ & $0 \cdot 43$ & $0 \cdot 10-0 \cdot 67$ \\
\hline \multicolumn{7}{|l|}{ Adjusted $^{*}$} \\
\hline Oestradiol (pg/ml) & $0 \cdot 10$ & $-0 \cdot 15$ to $0 \cdot 34$ & $0 \cdot 38$ & -0.01 to 0.68 & $0 \cdot 10$ & $-0 \cdot 43$ to $0 \cdot 45$ \\
\hline 2-Hydroxyoestrone (pg/ml) & $0 \cdot 28$ & $0 \cdot 04-0 \cdot 49$ & $0 \cdot 39$ & $0.03-0 \cdot 66$ & $0 \cdot 55$ & $0 \cdot 16-0 \cdot 79$ \\
\hline $16 \alpha$-Hydroxyoestrone $(\mathrm{pg} / \mathrm{ml})$ & $0 \cdot 39$ & $0 \cdot 16-0 \cdot 58$ & $0 \cdot 64$ & $0 \cdot 35-0 \cdot 81$ & $0 \cdot 58$ & $0 \cdot 19-0 \cdot 81$ \\
\hline
\end{tabular}

${ }^{\star} \rho_{\mathrm{Y} \mid \mathrm{X}}$ for adjusted values; adjusted for age, BMI, race group, lipids, physical activity level, alcohol, and having diabetes.

an aromatic hydroxyphenol structure. ${ }^{27}$ However, our data do not support that hypothesis; indeed, the opposite may be true. Although there was a statistically significant correlation between endogenous $\mathrm{E} 2$ and $\mathrm{F}_{2 \mathrm{a}}$-isoprostanes in postmenopausal women, the direction of the correlation was positive, not negative, and circulating levels of E2 were low. The same trend was observed with exogenous hormone use. The correlations of the oestrone metabolites with $\mathrm{F}_{2 \mathrm{a}}$-isoprostanes were positive, not negative, and fairly strong. Furthermore, the strengths of these associations were not diminished following adjustment for race, menopause status, BMI, lipids, smoking behaviour, vitamin $\mathrm{E}$ and iron supplement use, and level of alcohol consumption. This led us to conclude that higher levels of these oestrone metabolites were associated with greater oxidative stress and did not support our a priori hypothesis. However, these three aspects of oestrogen status do not reflect all oestrogen metabolites and it is possible that a nonmeasured analyte may have a different relationship than the very striking relationships we observed. For example, Tang et al. reported that 4-hydroyxoestrone was a potent inhibitor of lipid peroxidation in a cell culture system ${ }^{28}$ and Seeger et al. reported that 2methoxyoestrone and 2-hydroxyoestrone inhibited lipid peroxidation better than E2 and $16 \alpha$-OHE1 in pooled samples from healthy individuals. ${ }^{29}$ Evaluation of measures of the range of oestrogen metabolites in association with health-related states has been limited by the availability of reproducible assays that target specific metabolites and that can implemented in substantial size populations.

Our conclusion that E2 and oestrone metabolites were not acting as potent antioxidants is contingent on the integrity of the $\mathrm{F}_{2 \mathrm{a}}$ - isoprostanes to serve as informative markers of oxidative stress. $\mathrm{F}_{2 \mathrm{a}^{-}}$ isoprostanes, compounds produced by the free radical-induced peroxidation of arachidonic acid, ${ }^{30,31}$ have been characterized as superior markers of the in vivo oxidative stress response. ${ }^{15,32-34}$ Furthermore, elevated levels of $\mathrm{F}_{2 \mathrm{a}}$-isoprostanes are associated with behaviours or conditions thought to include oxidative stress such as smoking, ${ }^{35,36}$ alcohol consumption, ${ }^{17}$ hypercholesterolaemia, ${ }^{37,38}$ diabetes, ${ }^{39}$ liver disease, ${ }^{40}$ breast cancer $^{41}$ and atherosclerotic lesions. ${ }^{42}$ Indeed, we showed that $\mathrm{F}_{2 \mathrm{a}}$-isoprostanes values were more than doubled in women who smoked. Additionally, $\mathrm{F}_{2 \mathrm{a}}$-isoprostanes levels were also correlated with HDL-C in pre- and postmenopausal women who did not smoke and with LDL in postmenopausal women who smoked (data not shown).

To better understand the relationship between oestrogen and $\mathrm{F}_{2 \mathrm{a}}$-isoprostanes, we adjusted for or stratified by factors that had previously been identified as generating variation in $\mathrm{F}_{2 \mathrm{a}}$-isoprostane concentrations. In some, ${ }^{7,8}$ but not all, ${ }^{9,10}$ studies of postmenopausal women, oestrogen therapy acted like an antioxidant by diminishing the level of circulating oxidized LDL. However, responses to HT may have been inconsistently observed because preparations included progestin products as well as oestrogens. It has been reported that progesterone opposes the antioxidant actions of oestrogen on plasma LDL oxidation in primates. ${ }^{33}$

Health-related and lifestyle behaviours may influence oxidative capacity. ${ }^{34,43}$ We observed little modifying effect by diet of the association of oestrogens with $\mathrm{F}_{2 \mathrm{a}}$-isoprostanes, based on intakes of genistein, daidzein or total dietary fat. This is consistent with the 
findings of Block et al., ${ }^{12}$ who reported a very modest association with fruits, and none with vegetables, dairy foods, grains, meats or total fat intake. In contrast to diet, we identified a very strong association of oxidative stress with smoking behaviour. A greater proportion of African-American and Caucasian women smoked, compared to the low proportion of smokers in Chinese and Japanese women, leading to greatly exaggerated mean $\mathrm{F}_{2 \mathrm{a}}$-isoprostane values for African-American and Caucasian women. Although we evaluated the role of passive smoking, we found only an association with personal smoking behaviour. Women who reported more physical activity had lower $\mathrm{F}_{2 \mathrm{a}}$-isoprostane concentrations. Others have reported that endurance exercise is associated with increased plasma $\mathrm{F}_{2 \mathrm{a}}$-isoprostanes in dogs, ${ }^{44}$ horses ${ }^{45}$ and humans. ${ }^{46}$

This study had a number of strengths and limitations. A substantial number of women were evaluated with representation from four racial/ethnic groups. While this was a cross-sectional study, it was nested in a longitudinal study of the menopausal transition, so that menopausal status and HT use were definable within the context of those longitudinal observations. Despite these strengths, the crosssectional design precluded our ability to establish a temporal sequence between single-time measures of oestrogens and an $\mathrm{F}_{2 \mathrm{a}}$ isoprostane index of oxidative stress. Study protocol dictated that serum and urine be collected in the early follicular phase of the menstrual cycle rather than in the later follicular phase or luteal phase when oestrogen levels would be higher. As a result, we found that low oestrogen levels did not suppress oxidative stress; however, this does not necessarily preclude the possibility that higher oestrogen levels as seen later in the menstrual cycle might suppress oxidative stress. Initial criticism of the $\mathrm{F}_{2 \mathrm{a}}$-isoprostane measurement by EIA was largely overcome by the use of affinity columns to prepare the samples for analyses, as well as by improvement in the assays that we applied in our procedures. ${ }^{47}$ EIA from eluted samples correlated very well with other methods, including gas chromatography-mass spectrometry. ${ }^{48,49}$ A major advantage of the urinary measurement of $\mathrm{F}_{2 \mathrm{a}}$-isoprostanes was that they are not formed by ex vivo autooxidation in urine, and levels were stable even when urine was maintained at room temperature for as much as 10 days. ${ }^{50,51}$ In addition, the concentration of $\mathrm{F}_{2 \mathrm{a}}$-isoprostanes was unchanged with storage at $-20^{\circ} \mathrm{C} .{ }^{52,53}$ Values from repeated days of urinary excretion tended to be the same with low intrasubject CVs in persons, whether they were healthy or diseased. ${ }^{11,32,36,51}$ Little diurnal variation is observed, and therefore measurement of $\mathrm{F}_{2 \mathrm{a}}$-isoprostanes in a single early morning sample has been described as adequate to represent the daily isoprostane excretion in humans. ${ }^{52}$

In summary, these data indicate major differences in $\mathrm{F}_{2 \mathrm{a}^{-}}$ isoprostanes between smoking and nonsmoking women across the menopause transition. However, there was no evidence that the serum measure of early follicular phase E2 or urinary oestrone metabolite measures were acting as antioxidants; indeed, the strong adjusted and unadjusted positive correlations between the oestrone metabolites and $\mathrm{F}_{2 \mathrm{a}}$-isoprostanes suggest an active metabolic environment associated with the generation of free radicals. This study refutes the commonly held hypothesis that levels of endogenous E2 or its oestrone metabolites favourably modify oxidative stress through a decrease in $\mathrm{F}_{2 \mathrm{a}}$-isoprostanes.

\section{Acknowledgements}

The Study of Women's Health Across the Nation (SWAN) and the SWAN Repository have grant support from the National Institutes of Health (NIH), Department of Health and Human Services (DHHS), through the National Institute on Ageing, the National Institute of Nursing Research and the NIH Office of Research on Women's Health (Grants AG17104, AG017719, NR004061; AG012505, AG012535, AG012531, AG012539, AG012546, AG012553, AG012554, AG012495, AG17104). The oestrogen metabolites and isoprostane data were the result of an oestrogen metabolism grant for assay of urine samples from the SWAN Repository (AG17104, AG017719).

This report is based on samples from the SWAN Core Repository. If scientists are interested in developing studies based on this resource, a description of the SWAN Core and DNA Repositories and how to obtain access to the resources can be found at www.swanrepository.org.

\section{References}

1 Praticò, D., Rockach, J., Lawson, J. \& FitzGerald, G.A. (2004) $\mathrm{F}_{2}$ isoprostanes as indices of lipid peroxidation in inflammatory diseases. Chemistry and Physics of Lipids, 128, 165-171.

2 Halliwell, B. (1998) Can oxidative DNA damage be used as a biomarker of cancer risk in humans? Problems, resolutions, and preliminary results from nutritional supplementation studies. Free Radical Research, 29, 469-486.

3 Arteaga, E., Rojas, A., Villaseca, P., Bianchi, M., Arteaga, A. \& Durán, D. (1998) In vitro effect of estradiol, progesterone, testosterone, and of combined estradiol/progestins on low density lipoprotein (LDL) oxidation in postmenopausal women. Menopause, 5, 16-23.

4 Moosmann, B. \& Behl, C. (1999) The antioxidant neuroprotective effects of estrogens and phenolic compounds are independent from their estrogenic properties. Proceedings of the National Academy of Sciences of the United States of America, 96, 8867-8872.

5 Witztum, J.L. \& Steinberg, D. (1991) Role of oxidized low density lipoprotein in atherogenesis. Journal of Clinical Investigation, 88, 1785-1792.

6 Cracowski, J.L. \& Ormezzano, O. (2004) Isoprostanes, emerging biomarkers and potential mediators in cardiovascular diseases. European Heart Journal, 25, 1675-1678.

7 Sack, M.N., Rader, D.J. \& Cannon, R.O. III (1994) Oestrogen and inhibition of oxidation of low-density lipoproteins in postmenopausal women. Lancet, 343, 269-270.

8 Wakatsuki, A., Ikenoue, N. \& Sagara, Y. (1998) Effects of estrogen on susceptibility to oxidation of low-density and high-density lipoprotein in postmenopausal women. Maturitas, 28, 229-234.

9 Hermenegildo, C., García-Martínez, M.C., Tarín, J.J. \& Cano, A. (2002) Inhibition of low-density lipoprotein oxidation by the pure antiestrogens ICI 182780 and EM-652 (SCH 57068). Menopause, 9, 430-435.

10 Santanam, N., Shern-Brewer, R., McClatchey, R., Castellano, P.Z., Murphy, A.A., Voelkel, S. \& Parthasarathy, S. (1998) Estradiol as an antioxidant: incompatible with its physiological concentrations and function. Journal of Lipid Research, 39, 2111-2118.

11 Ide, T., Tsutsui, H., Ohashi, N., Hayashidani, S., Suematsu, N., Tsuchihashi, M., Tamai, H. \& Takeshita, A. (2002) Greater oxidative stress in healthy young men compared with premenopausal women. Arteriosclerosis, Thrombosis, and Vascular Biology, 22, 438-442. 
12 Block, G., Dietrich, M., Norkus, E.P., Morrow, J.D., Hudes, M., Caan, B. \& Packer, L. (2002) Factors associated with oxidative stress in human populations. American Journal of Epidemiology, 156, 274285.

13 Keaney, J.F. Jr, Larson, M.G., Vasan, R.S., Wilson, P.W., Lipinska, I., Corey, D., Massaro, J.M., Sutherland, P., Vita, J.A. \& Benjamin, E.J. (2003) Obesity and systemic oxidative stress: clinical correlates of oxidative stress in the Framingham Study. Arteriosclerosis, Thrombosis, and Vascular Biology, 23, 434-439.

14 Helmersson, J., Mattsson, P. \& Basu, S. (2002) Prostaglandin $F_{20}$ metabolite and $\mathrm{F}_{2}$-isoprostane excretion rates in migraine. Clinical Science, 102, 39-43.

15 Morrow, J.D. (2005) Quantification of isoprostanes as indices of oxidant stress and the risk of atherosclerosis in humans. Arteriosclerosis, Thrombosis, and Vascular Biology, 25, 279-286.

16 Roberts, L.J. II \& Morrow, J.D. (2000) Measurement of $\mathrm{F}_{2}$-isoprostanes as an index of oxidative stress in vivo. Free Radical Biology and Medicine, 28, 505-513.

17 Hartman, T.J., Baer, D.J., Graham, L.B., Stone, W.L., Gunter, E.W., Parker, C.E., Albert, P.S., Dorgan, J.F., Clevidence, B.A., Campbell, W.S., Tomer, K.B., Judd, J.T. \& Taylor, P.R. (2005) Moderate alcohol consumption and levels of antioxidant vitamins and isoprostanes in postmenopausal women. European Journal of Clinical Nutrition, 59, $161-168$

18 Sowers, M.F., Crawford, S., Sternfeld, B., Morgenstein, D., Gold, E., Greendale, G., Evans, D., Neer, R., Matthews, K., Sherman, S., Lo, A., Weiss, G. \& Kelsey, J. (2000) Design, survey sampling and recruitment methods of SWAN: a multi-center, multi-ethnic, community-based cohort study of women and the menopausal transition. In: R.A. Lobo, J. Kelsey, R. Marcus eds. Menopause: Biology and Pathobiology. Academic Press, San Diego, 175-188.

19 Klug, T.L., Bradlow, H.L. \& Sepkovic, D.W. (1994) Monoclonal antibody-based enzyme immunoassay for simultaneous quantitation of 2- and 16 $\alpha$-hydroxyestrone in urine. Steroids, 59, 648-655.

20 Myers, G.L., Cooper, G.R., Winn, C.L. \& Smith, S.J. (1989) The Centers for Disease Control-National Heart, Lung, and Blood Institute Lipid Standardization Program: an approach to accurate and precise lipid measurements. Clinical Laboratory Medicine, 9, 105-135.

21 Ferris, B.G. (1978) Epidemiology Standardization Project (American Thoracic Society). American Review of Respiratory Disease, 118, 1-20.

22 Coghlin, J., Hammond, S.K. \& Gann, P.H. (1989) Development of epidemiologic tools for measuring environmental tobacco smoke exposure. American Journal of Epidemiology, 130, 696-704.

23 Sternfeld, B., Ainsworth, B.E. \& Quesenbury, C.P. Jr (1999) Physical activity patterns in a diverse population of women. Preventive Medicine, 28, 313-323.

24 Block, G., Hartman, A.M., Dresser, C.M., Carroll, M.D., Gannon, J. \& Gardner, L. (1986) A data-based approach to diet questionnaire design and testing. American Journal of Epidemiology, 124, 453469 .

25 Reinli, K. \& Block, G. (1996) Phytoestrogen content of foods - a compendium of literature values. Nutrition and Cancer, 26, 123-148.

26 Sowers, M.R., Crawford, S., McConnell, D.S., Randolph, J.F. Jr, Gold, E.B., Wilkin, M.K. \& Lasley, B. (2006) Selected diet and lifestyle factors are associated with estrogen metabolites in a multi-racial/ ethnic population of women. Journal of Nutrition, 136, 1588-1595.

27 Nathan, L. \& Chaudhuri, G. (1998) Antioxidant and prooxidant actions of estrogens: potential physiological and clinical implications. Seminars in Reproductive Endocrinology, 16, 309-314.

28 Tang, M., Abplanalp, W., Ayres, S. \& Subbiah, M.T. (1996) Superior and distinct antioxidant effects of selected estrogen metabolites on lipid peroxidation. Metabolism: Clinical and Experimental, 45, 411414.

29 Seeger, H., Mueck, A.O. \& Lippert, T.H. (1997) Effect of estradiol metabolites on the susceptibility of low density lipoprotein to oxidation. Life Sciences, 61, 865-868.

30 Morrow, J.D., Hill, K.E., Burk, R.F., Nammour, T.M., Badr, K.F. \& Roberts, L.J. II (1990) A series of prostaglandin $\mathrm{F}_{2}$-like compounds are produced in vivo in humans by a non-cyclooxygenase, free radical-catalyzed mechanism. Proceedings of the National Academy of Sciences of the United States of America, 87, 9383-9387.

31 de Zwart, L.L., Meerman, J.H., Commandeur, J.N. \& Vermeulen, N.P. (1999) Biomarkers of free radical damage applications in experimental animals and humans. Free Radical Biology and Medicine, 26, 202-226.

32 Cracowski, J.L., Cracowski, C., Bessard, G., Pepin, J.L., Bessard, J., Schwebel, C., Stanke-Labesque, F. \& Pison, C. (2001) Increased lipid peroxidation in patients with pulmonary hypertension. American Journal of Respiratory and Critical Care Medicine, 164, 1038-1042.

33 McKinney, K.A., Duell, P.B., Wheaton, D.L., Hess, D.L., Patton, P.E., Spies, H.G. \& Burry, K.A. (1997) Differential effects of subcutaneous estrogen and progesterone on low-density lipoprotein size and susceptibility to oxidation in postmenopausal rhesus monkeys. Fertility and Sterility, 68, 525-530.

34 Richelle, M., Turini, M.E., Guidoux, R., Tavazzi, I., Métairon, S. \& Fay, L.B. (1999) Urinary isoprostane excretion is not confounded by the lipid content of the diet. FEBS Letters, 459, 259-262.

35 Morrow, J.D., Frei, B., Longmire, A.W., Gaziano, J.M., Lynch, S.M., Shyr, Y., Strauss, W.E., Oates, J.A. \& Roberts, L.J. II (1995) Increase in circulating products of lipid peroxidation ( $\mathrm{F}_{2}$-isoprostanes) in smokers. New England Journal of Medicine, 332, 1198-1203.

36 Reilly, M., Delanty, N., Lawson, J.A. \& FitzGerald, G.A. (1996) Modulation of oxidant stress in vivo in chronic cigarette smokers. Circulation, 94, 19-25.

37 Davi, G., Alessandrini, P., Mezzetti, A., Minotti, G., Bucciarelli, T., Costantini, F., Cipollone, F., Bon, G.B., Ciabattoni, G. \& Patrono, C. (1997) In vivo formation of 8-epi-prostaglandin $\mathrm{F}_{2 \alpha}$ is increased in hypercholesterolemia. Arteriosclerosis, Thrombosis, and Vascular Biology, 17, 3230-3235.

38 Reilly, M.P., Praticò, D., Delanty, N., DiMinno, G., Tremoli, E., Rader, D., Kapoor, S., Rokach, J., Lawson, J. \& FitzGerald, G.A. (1998) Increased formation of distinct $\mathrm{F}_{2}$ isoprostanes in hypercholesterolemia. Circulation, 98, 2822-2828.

39 Davi, G., Ciabattoni, G., Consoli, A., Mezzetti, A., Falco, A., Santarone, S., Pennese, E., Vitacolonna, E., Bucciarelli, T., Costantini, F., Capani, F. \& Patrono, C. (1999) In vivo formation of 8-iso-prostaglandin $F_{2 \alpha}$ and platelet activation in diabetes mellitus: effects of improved metabolic control and vitamin E supplementation. Circulation, 99, 224-229.

40 Pratico, D., Iuliano, L., Basili, S., Ferro, D., Camastra, C., Cordova, C., FitzGerald, G.A. \& Violi, F. (1998) Enhanced lipid peroxidation in hepatic cirrhosis. Journal of Medical Investigation, 46, 51-57.

41 Kumar, K., Thangaraju, M. \& Sachdanandam, P. (1991) Changes observed in antioxidant system in the blood of postmenopausal women with breast cancer. Biochemistry International, 25, 371-380.

42 Oguogho, A., Kritz, H., Wagner, O. \& Sinzinger, H. (2001) 6-oxo$\mathrm{PGF}_{1 \alpha}$ and 8-epi-PGF $2 \alpha$ in the arterial wall layers of various species: a comparison between intact and atherosclerotic areas. Prostaglandins, Leukotrienes, and Essential Fatty Acids, 64, 167-171.

43 Gopaul, N.K., Zacharowski, K., Halliwell, B. \& Änggard, E.E. (2000) Evaluation of the postprandial effects of a fast-food meal on human plasma $\mathrm{F}_{2}$-isoprostane levels. Free Radical Biology and Medicine, 28, 806-814. 
44 Hinchcliff, K.W., Reinhart, G.A., DiSilvestro, R., Reynolds, A., Blostein-Fujii, A. \& Swenson, R.A. (2000) Oxidant stress in sled dogs subjected to repetitive endurance exercise. American Journal of Veterinary Research, 61, 512-517.

45 Kirschvink, N., Smith, N., Fievez, L., Bougnet, V., Art, T., Degand, G., Marlin, D., Roberts, C., Genicot, B., Lindsey, P. \& Lekeux, P. (2002) Effect of chronic airway inflammation and exercise on pulmonary and systematic antioxidant status of healthy and heaves-affected horses. Equine Veterinary Journal, 34, 563-571.

46 Mastaloudis, A., Leonard, S.W. \& Traber, M.G. (2001) Oxidative stress in athletes during extreme endurance exercise. Free Radical Biology and Medicine, 31, 911-922.

47 Proudfoot, J., Barden, A., Mori, T.A., Burke, V., Croft, K.D., Beilin, L.J. \& Puddey, I.B. (1999) Measurement of urinary $\mathrm{F}_{2}$-isoprostanes as markers of in vivo lipid peroxidation - a comparison of enzyme immunoassay with gas chromatography/mass spectrometry. Analytical Biochemistry, 272, 209-215.

48 Devaraj, S., Hirany, S.V., Burk, R.F. \& Jialal, I. (2001) Divergence between $\mathrm{LDL}$ oxidative susceptibility and urinary $\mathrm{F}_{2}$-isoprostanes as measures of oxidative stress in Type 2 diabetes. Clinical Chemistry, 47, 1974-1979.
49 Walsh, S.W., Vaughan, J.E., Wang, Y. \& Roberts, L.J. II (2000) Placenta isoprostane is significantly increased in preeclampsia. FASEB Journal, 14, 1289-1296.

50 Meagher, E.A., Barry, O.P., Lawson, J.A., Rokach, J. \& FitzGerald, G.A. (2001) Effects of vitamin E on lipid peroxidation in healthy persons. Journal of the American Medical Association, 285, 11781182.

51 Praticň, D., Barry, O.P., Lawson, J.A., Adiyaman, M., Hwang, S.W., Khanapure, S.P., Iuliano, L., Rokach, J. \& FitzGerald, G.A. (1998) $\mathrm{IPF}_{2 \alpha}-\mathrm{I}$ : an index of lipid peroxidation in humans. Proceedings of the National Academy of Sciences of the United States of America, 95, 3449-3454.

52 Wang, Z., Ciabattoni, G., Créminon, C., Lawson, J., FitzGerald, G.A., Patrono, C. \& Maclouf, J. (1995) Immunological characterization of urinary 8-epi-prostaglandin $\mathrm{F}_{2 \alpha}$ excretion in man. Journal of Pharmacology and Experimental Therapeutics, 275, 94-100.

53 Ohashi, N. \& Yoshikawa, M. (2000) Rapid and sensitive quantification of 8-isoprostaglandin $\mathrm{F}_{2 \alpha}$ in human plasma and urine by liquid chromatography-electrospray ionization mass spectrometry. Journal of Chromatography B: Biomedical Sciences and Applications, 746, 17-24. 